$\xi_{p}$

\title{
Field Investigation on Limestone Treatment using Fissure Grouting Method
}

\author{
Prakash Ananthan ${ }^{1}$, Leong Sing Wong ${ }^{2 *}$ \\ ${ }^{1,2}$ College of Graduate Studies, Universiti Tenaga Nasional, \\ IKRAM-UNITEN Road, 43000 Kajang, Selangor, Malaysia \\ *Corresponding author E-mail: wongls@uniten.edu.my
}

\begin{abstract}
This paper documents a field study on fissure grouting for limestone with a specific aim to investigate grout injection into the rock in order to reduce its permeability. The study focused on grouting in advance of excavation and it is applicable to grouting carried out to seal exposed rock surfaces. Investigation concentrated on the need to carry out fissure grouting to seal off excessive water entering the excavation through fractured rocks. In this case, the grout mixtures involved a combination of Ordinary Portland cement (OPC) and bentonite with appropriate amount of water. The grouting was performed at each stage until the grout flow rate and pressure reached a constant level for the last five minutes. If the stage of grouting in a borehole required more grout, this implies that there exist more fissure and cracks in the rock. The ultimate outcome of the rock fissure grouting was to obtain a good feed into limestone rock fissures, and thus, the process involved high injection pressure. The minimum grouting pressure was indicated as the hydrostatic pressure plus line loss pressure. To ensure that the outcome was achieved, it was recommended for an additional two bar pressure to be maintained as hydrostatic pressure.
\end{abstract}

Keywords: Fissure grouting; Limestone; Ordinary Portland cement; Bentonite; Grouting pressure

\section{Introduction}

Fissure grouting involves the process of injecting grout into inaccessible and interconnected pore spaces in rock of which the volume of the pores are unknown. It is widely used for sealing discontinuities which affect the permeability and strength of a rock mass [1]. It is usually performed by drilling holes into the applied area to reach open cracks, joints, fissures or cavities, and then subjected to pumping under pressure balanced and stabilized grout mixes using a combination of cement, water and additives. The grout can be made of a mixture of water, Ordinary Portland cement and bentonite. The purpose of grouting is to fill rock cavities, thereby strengthening and reducing the permeability of rock so that it can support the foundation of structures. It is an effective approach for enhancing the engineering characteristics of rocks and hindering groundwater leaking in construction projects as evident in several studies [2-5]. Although such method for treating rock cavities for foundation support is already established, little attention was paid on the field investigation of the fissure grouting method in treating rock cavities. Such trend of research within the field of geotechnical engineering is in contrast with that of research on mining sand treated with clay and hydrated lime which had been widely investigated as evident in the study of Thian and Lee [6]

Until recently, however, this method has been predominantly empirical, with grouting performed by injection and the ground heaving being closely observed. During fissure grouting process, the behavior of the grout fill up in the underground cannot be characterized, despite its detrimental effect on the efficiency and safety of the process. The empirical nature of the procedure can lead to uncertainties, such as a short falling compensation or compensa- tion occurring at a different location from where the grout was injected [7]. It can also result in accidental ground cracking under high pressure. The efficiency of fissure grout in rock treatment is affected by various parameters such as the specific properties of the grout (water to cement ratio, grouting pressure and flow rate of grout admixture), the rock properties (density, porosity and shear strength) and the boundary conditions.

In the past, numerous studies were done on pressure grouting [813]. Notably, Wang et al. [12] conducted experimental investigation on pressure grouting in sand in order to study the grout evolution and diffusion process upon pressure grouting injection in the soil. In the study, cement grout was tested for the purpose of evaluating its compressive strength and bleeding behavior. It was discovered from the experimental evaluation that at a water to cement ratio of 0.5 , the 28 -day compressive strength of the cement grout was found to be $37 \mathrm{MPa}$ which is higher than that of a standard concrete. Moreover, the bleeding ratio $(d V / V$, defined as the volume of clear water segregated on the top divided by the original grout volume) of the cement grout at the same water to cement ratio was found to be only $1.5 \%$ which is considerably low. This implies that loss in volume by bleeding which generated voids inside the grout mix that affected the properties and performance of the grout was relatively low.

In another study, Zhang et al. [13] observed the effect of grouting material on leakage-induced pore pressure change. The study predicted the grouting effect on leakage-induced tunnels and ground response in saturated soils. It was noticed from the results of the study that the grouting material had the capability to decrease the change in pore water pressure. This provides a clear indication that the grouting material on the tunnel leakage is influenced by the permeability of the tunnel lining. 
Despite these published findings, there remains a research gap regarding the study on controlling factors that can affect the performance of cement-bentonite grout in fissure grouting method to treat rock cavities for ground improvement in real time monitoring. As such, it is justifiable for the field study to be carried out in order to fully comprehend such phenomenon. The selected site for the field study is the MRT site line 2 which is located at Bandar Malaysia Station at Sungai Besi, Kuala Lumpur, Malaysia. In the grouting process, the addition of cement to bentonite resulted in a suspension which has interesting synergistic properties and this is widely used as a permeation grout.

\section{Fissure Grouting Fieldwork Sequence and Termination Criteria}

The method adopted for the fissure grouting fieldwork under study is known as upstage grouting method. The method carried out in phases of maximum 5 meters from the borehole base was also applied in rock grouting work at the Cityring metro project in the urban area of Copenhagen, Denmark as reported by Paulatto \& Carstensen [11]. The fieldwork sequence of fissure grouting is described in the following. Boring work was commenced at the predetermined grout point to a final treatment depth using Downthe-hole (DTH) hammer (Fig. 1). During drilling, the rock penetration rate was recorded continuously. The grouting was then carried out in stages, ascending from the base of the hole. It is important to note that before the grouting work can be done at the site, flushing of ground water from the bore holes must be carried out (Fig. 2). Depending on the rock quality and grout intake in the primary holes, if the grout intake for the primary hole was 5 cubic meter or greater per stage without refusal for a prescribed pressure at a given depth, then the secondary grout hole would be introduced at the adjacent location after completion of grouting to the primary holes. During the grouting process of each grouting point, four different types of grout mixture would be introduced in stages depending on the grout intake. Fig. 3 shows a typical grout mixture and Table 1 indicates specifications of four different types of grout mixture under study. The dosage of grout should be added from thin to thicker mix. The grout should consist of a mixture of Ordinary Portland cement (OPC) with bentonite and portable water with the mixing process done using a high speed colloidal mixer $(1500 \mathrm{rpm})$. As a rule, the grouting work should be carried out from lean mix to thicker mix, depending on the rock condition. The acceptable range of grout density for each of the grout mixtures is shown in Table 2.

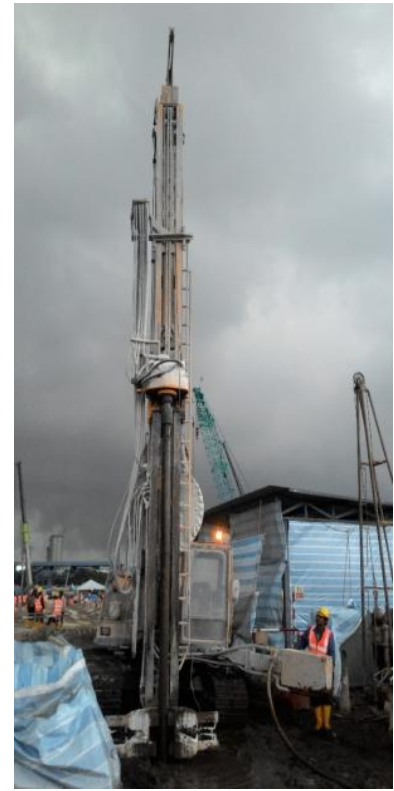

Fig. 1: The boring work at a predetermined grouting point at the site

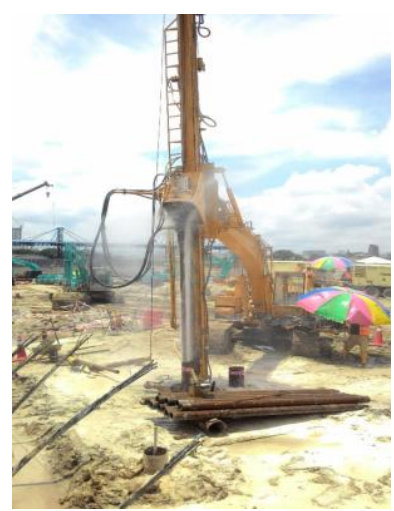

Fig. 2: Flushing of ground water from a bore hole at the site

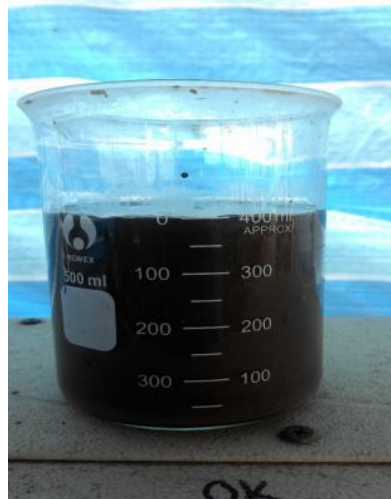

Fig. 3: A typical grout mixture under study

Table 1: Specifications of the grout mixtures under study

\begin{tabular}{|c|c|c|c|c|c|}
\hline $\begin{array}{c}\text { Mix } \\
\text { No. }\end{array}$ & $\begin{array}{c}\text { Type of } \\
\text { cement }\end{array}$ & $\begin{array}{c}\text { Cement } \\
(\mathrm{kg})\end{array}$ & $\begin{array}{c}\text { Water } \\
(\mathrm{kg})\end{array}$ & $\begin{array}{c}\text { Bentonite } \\
(\mathrm{kg})\end{array}$ & $\begin{array}{c}\text { Water to } \\
\text { cement ratio }\end{array}$ \\
\hline 1 & OPC & 50 & 100 & 3 & 2.0 \\
\hline 1A & OPC & 50 & 75 & 1.7 & 1.5 \\
\hline 1B & OPC & 100 & 100 & 1.2 & 1.0 \\
\hline 1C & OPC & 100 & 80 & 0 & 0.8 \\
\hline
\end{tabular}

Table 2: Acceptable range of grout density

\begin{tabular}{|c|c|c|}
\hline Mix No. & $\begin{array}{c}\text { Water to cement } \\
\text { ratio }\end{array}$ & $\begin{array}{c}\text { Acceptable range for grout density } \\
\left(\mathrm{Mg} \mathrm{m}^{-3}\right)\end{array}$ \\
\hline 1 & 2.0 & $1.26-1.32$ \\
\hline $1 \mathrm{~A}$ & 1.5 & $1.34-1.40$ \\
\hline $1 \mathrm{~B}$ & 1.0 & $1.48-1.54$ \\
\hline $1 \mathrm{C}$ & 0.8 & $1.57-1.63$ \\
\hline
\end{tabular}

The targeting point of the rock fissure grouting was to obtain a good grout feed into rock fissures, and as such, high injection pressure was required. The minimum grouting pressure should be hydrostatic pressure plus line loss pressure. To ensure that the purpose of the grouting work was achieved, it was recommendable for additional two bar pressure to be maintained above the hydrostatic pressure. The recommended grout pressures with respect to various ground depths are indicated in Table 3.

Table 3: Recommended grout pressures at various ground depths

\begin{tabular}{|c|c|}
\hline Depth $(\mathrm{m})$ & Recommended holding pressure (Bar) \\
\hline $0-5$ & 2 \\
\hline $5-10$ & 4 \\
\hline $10-15$ & 6 \\
\hline $15-20$ & 8 \\
\hline $20-25$ & 10 \\
\hline $25-30$ & 12 \\
\hline $30-35$ & 14 \\
\hline $35-40$ & 16 \\
\hline
\end{tabular}

The final pressure (recommended holding pressure) must be maintained for a predetermined period (not less than five minutes) with a reduced flow rate of $3 \mathrm{~L} / \mathrm{min}$. When the grout volume reached a predetermine amount ( 5 cubic meter), the grouting work would be 
suspended for at least 24 hours in order to allow setting of the grout. After this time interval, the grouting work would be resumed (where suspension of grout occurred, the secondary grout holes should be added there after).

\section{Results and Discussion}

To achieve a good result for fissure grouting, it is of great importance to highlight some criteria that must be followed. The rock fissure grouting procedure was carried out in accordance to the standard of BS EN 12715 [14]. Rock fissure grouting was performed by the injection of cement. All grouting materials were stored in such a manner that they were protected from any adverse effect due to tropical climate influence. Essentially, the materials for the making of the grout mixtures must be non-toxic. Mixing water for grouts must be clean and portable. The proposed grout mixtures should have sufficient durability to ensure that they remained effective for the intended purpose and duration. All holes that were drilled for grouting or testing (before, during or after grouting) should be backfilled with a stable cement grout over the full length of the hole. In addition, the selection of grouting pressure has a great influence over the quality of the grouting work Rafi \& Stille [15] justified that if a low pressure is chosen, the grout may not penetrate into the network of natural fractures within the rock mass while high pressure may cause some of fractures to dilate, so that the spread of the grout is uncontrolled and permanent deformation of rock mass occur. A daily record for the grouting work should be included with the following information; the number of the holes that were drilled with the depth; the stages grouted; the type of grout; grout volume; final pressure and hold time for each stage of grout injection; the result from test carried out on the grout used; as well as the remarks on issues affecting the grouting. To achieve reliable results, it is necessary to note that before any grouting work is carried out, the grout needs to be assessed at site to meet the bleeding, viscosity, density and cubic strength requirements. In that sense, the grout needs to demonstrate capability to seal fissures in rock mass in a way that can significantly reduce its porosity and contribute to the strengthening of the rocky ground.

Fig. 4 shows the volume versus time; flow-rate versus time and pressure versus time that reflect the fissure grouting performance at site point C-P014 (20 to $25 \mathrm{~m}$ ). A good result can be observed from the figure considering the trend that there was a progressive increase in the volume of the injected grout over time. Similar pattern of increase in the grout volume over time in pressure grouting process can also be traced from the published work of Wang et al. [12]. The increase in the volume of the injected grout continued until it reached a constant level of $242 \mathrm{~L}$ for the last 5 minutes. At this stage, the grouting pressure and the flow-rate were maintained for not less than five minutes. As observed in Fig. 4 , constant values of the grouting pressure of 12 bars and flow-rate below ( $3 \mathrm{~L} / \mathrm{min}$ ) were achieved in the final stage. In such case, termination of the grouting work for this stage can be done considering the fissures and cracks in the rock were successfully treated.

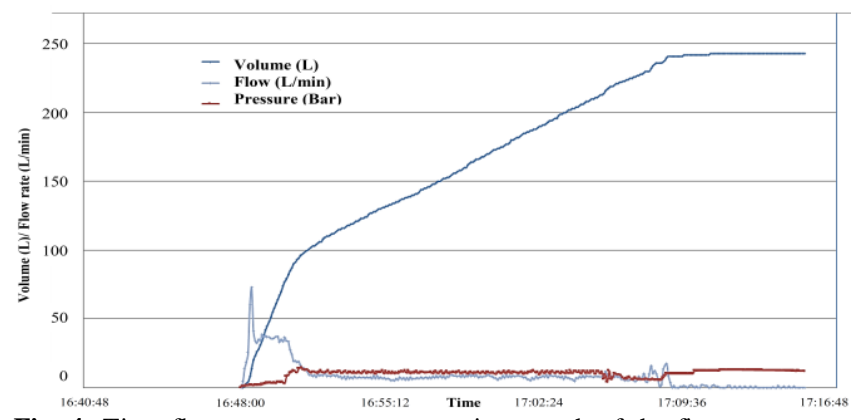

Fig. 4: Time-flow-rate-pressure versus time graph of the fissure grout at site point C-P014 (20 to $25 \mathrm{~m}$ )
Fig. 5 depicts the volume versus time; flow-rate versus time and pressure versus time that represent the fissure grouting performance at site point C-P017 (11.655 to $15 \mathrm{~m})$. No clear trend could be observed from the result. The grouting pressure and the flowrate were not maintained at consistent values. A grouting pressure of 8 bars and flow-rate of $3 \mathrm{~L} / \mathrm{min}$. were not achieved at the stage. With respect to that, it was vital to terminate the grouting work at this stage and mark the hole as suspended hole. Further treatment of using fissure grouting method needed to be done at a nearby point. In addition, $\mathrm{Li}$ et al. [16] stipulated that for the grouting work to be done effectively, the compressive strength and plastic shear stress of cured grout at the flow cross-section boundary should be larger than the hydrostatic pressure so that grout plug is induced.

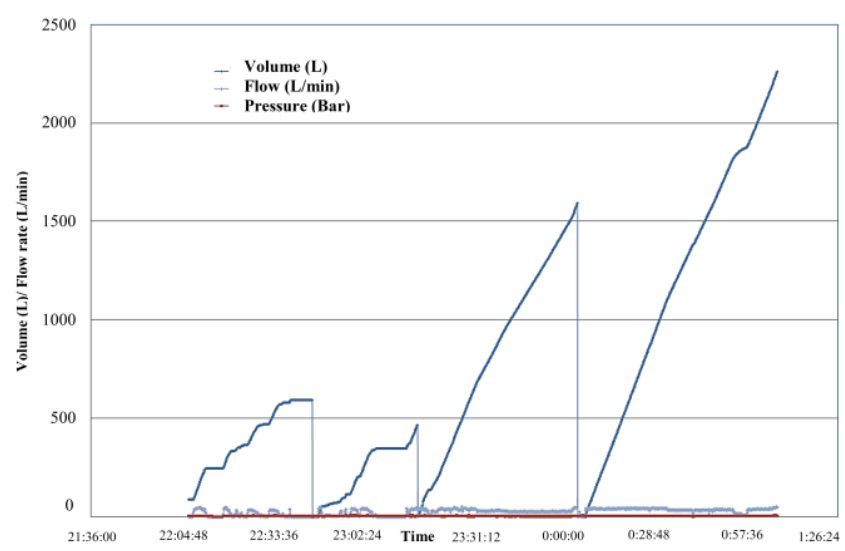

Fig. 5: Time-flow-rate-pressure versus time graph of the fissure grout at site point C-P017 (11.655 to $15 \mathrm{~m})$

\section{Conclusion}

Based on the field study, it is conclusive that rock fissure grouting is a viable method to treat the underground rock for the ground improvement work. The grout became smoother with the addition of an optimal proportion of Ordinary Portland cement and bentonite. The injected grout was able to penetrate through and seal small cracks and minor fissures in the rock. When the pressure and the required flow rate were achieved, it is indicative that the rock fissures had been fully treated. With reference to the concluding remarks of the result outcomes, it is recommendable for further investigations to be done regarding the feasible amounts of grout inflow during the rock grouting process and correlate the findings with the effectiveness in sealing rock fissures underground. This will further consolidate understanding regarding the mechanism of improvement in the cementation process of fissures in rocks for construction projects.

\section{Acknowledgement}

The authors would like express their sincere gratitude to GEOHAN SDN. BHD., a Foundation and Geotechnical Specialist in Malaysia, for providing technical support to have the field tests to be done at Sungai Besi project site in Bandar Malaysia. Acknowledgement is also expressed to Universiti Tenaga Nasional for supporting the research work through UNITEN BOLD Research Grant 2017 (Project code number: 10289176/B/2017/17).

\section{References}

[1] Chen Y, Nishiyama T, Terada M \& Iwamoto Y (2000). A fluorescent approach to the identification of grout injected into fissures and pore spaces. Engineering Geology 56, 395-401.

[2] Kikuchi K, Igari T, Mito Y \& Utsuki S (1997). In situ experimental studies on improvement of rock masses by grouting treatment. In- 
ternational Journal of Rock Mechanics and Mining Sciences 34, 3 4.

[3] Sui W, Liu J, Hu W, Qi J \& Zhan K (2015). Experimental investigation on sealing efficiency of chemical grouting in rock fracture with flowing water. Tunneling and Underground Space Technology 50, 239-249.

[4] Rafi JY \& Stille H (2014). Control of rock jacking considering spread of grout and grouting pressure. Tunneling and Underground Space Technology 40, 1-15.

[5] Salimian MH, Baghbanan A, Hashemolhoseini H, Dehghanipoodeh M \& Norouzi S (2017). Effect of grouting on shear behavior of rock joint. International Journal of Rock Mechanics \& Mining Sciences 98, 159-166.

[6] Thian SY \& Lee CY (2012). Shear strength behaviour of mining sand treated with clay and hydrated lime. International Journal of Civil and Structural Engineering 3, 57-69.

[7] Paans WJM (2002). The influence zone and effectiveness of fracture grouting on piled foundations. M.Sc. thesis. Delft University of Technology, The Netherlands.

[8] Zhang QS, Zhang LZ, Liu RT, Li SC \& Zhang QQ (2017). Grouting mechanism of quick setting slurry in rock fissure with consideration of viscosity variation with space. Tunneling and Underground Space Technology 70, 262-273.

[9] Bohloli B, Morgana EK, Grøvb E, Skjølsvoldb O, Hognestadc HO (2018). Strength and filtration stability of cement grouts at room and true tunneling temperatures. Tunneling and Underground Space Technology 71, 193-200.

[10] Zhang D, Fang Q \& Haicheng Lou H (2014). Grouting techniques for the unfavorable geological conditions of Xiang'an subsea tunnel in China. Journal of Rock Mechanics and Geotechnical Engineering 6, 438-446.

[11] Paulatto E \& Carstensen S (2017). Rock Grouting in Copenhagen Limestone - The Cityringen Experience. Procedia Engineering 191, 719-728.

[12] Wang, Q, Wang S, Sloan SW, Sheng D \& Pakzad R (2016). Experimental investigation of pressure grouting in sand. Soils and Foundations 56, 161-173.

[13] Zhang DM, Huang SK, Yin ZY, Ran LZ \& Huang HW (2017) Predicting the grouting effect on leakage-induced tunnels and ground response in saturated soils. Tunnelling and Underground Space Technology 65, 76-90.

[14] BS EN 12715. (2000). Execution of special geotechnical work.

[15] Rafi JY \& Stille H (2014). Control of rock jacking considering spread of grout and grouting pressure. Tunneling and Underground Space Technology 40, 1-15.

[16] Li S, Liu R, Zhang Q, \& Zhang X (2016). Protection against water or mud inrush in tunnels by grouting: A review. Journal of Rock Mechanics and Geotechnical Engineering 8, 753-766. 